\title{
The Epidemiology, Diagnosis and Treatment of H5N1, H1N1 and H7N9
}

\section{Jiaxian $\mathrm{Ou}^{1}$, Shuihua $\mathrm{Lu}^{2}$, Bo $\mathrm{Wu}^{3}$, Chunxue Bai ${ }^{1}$ and Yuanlin Song ${ }^{\star 1,2,3}$}

${ }^{1}$ Department of Pulmonary Medicine, Zhongshan Hospital, Qingpu Branch, and Shanghai Public Health , China

${ }^{2}$ Clinical Center, Fudan University, China

${ }^{3}$ Shanghai Respiratory Research Institute, China

On March 31, 2013, a novel avian viral (H7N9) infection was identified in Shanghai with fatal outcome [1]. Till May 10, 2013, 111 laboratory-confirmed H7N9 cases had been reported in Shanghai, Zhejiang, Jiangsu, Anhui, Henan and Beijing [2]; amongst which 27.0\% had died [3]. It reminded the public of precedent $\mathrm{H} 5 \mathrm{~N} 1$ and $\mathrm{H} 1 \mathrm{~N} 1$ pandemics which had swept across the globe with substantial infection and mortality. In 1997, H5N1 pandemic was first proclaimed with 18 infections and 6 related deaths in Hong Kong [4,5]. It was gradually resolved to sporadicity via depopulation of birds and poultry but broke out yet again in 2003 to cause 424 confirmed cases and 261 deaths as of May 15, 2009 [5]. H1N1, a product of multiple assortments between avian, swine and human influenza viruses, initiated another pandemic in Mexico in 2009 which spread across the globe and resulted in 11034 cases and 85 deaths in 41 countries as of May 21, 2009 [6].

$\mathrm{H} 5 \mathrm{~N} 1, \mathrm{H} 1 \mathrm{~N} 1$ and the novel H7N9 are type A influenza viruses belonging to the RNA viral family Orthomyxoviridae. Unlike types $\mathrm{B}$ and $\mathrm{C}$ of the family, type $\mathrm{A}$ presents rapid evolution and variations in antigenicity, pathogenicity and host specificity capable of avian and mammalian infections. According to the antigenicity of Hemagglutinin (HA) and Neuraminidase (NA) molecules, type A viruses are subdivided into 16 HA subtypes (H1-H16) and 9 NA subtypes (N1-N9). Generally sporadic, introduction of a novel HA subtype in the human population through genetic reassortment or inter-species transmission may initiate an influenza pandemic. An infected individual may develop contagious respiratory conditions of influenza characterized by high fever, cough, headache, malaise and inflammation of the upper and lower respiratory tract. In severe cases, complications such as pneumonia, hemorrhagic bronchitis, multiorgan dysfunction, central nervous system involvement and death may result. Specifically, H5N1 viruses replicate mainly in the lower respiratory tract $[7,8]$ and disease severity correlates directly with viral load to cause severe pneumonia, lymphopenia, hypercytokinemia and hyperchemokinemia [7-12]. Pulmonary manifestation of H1N1 infection varies between febrile upper respiratory tract infection, fulminant primary viral pneumonia and secondary bacterial pneumonia with Acute Respiratory Distress Syndrome (ARDS). The novel H7N9 infection, similarly, has been observed with fulminant pneumonia, respiratory failure and ARDS [9]. Among H1N1 and H7N9, rhabdomyolysis and encephalopathy, at midst other extrapulmonary manifestation, have been reported [13-15].

While clinical manifestation serves as a means of tentative diagnosis, confirmative tests should be implemented to differentiate the possibilities of other viral or bacterial infections. Basically, they include viral isolation, serological tests, rapid antigen tests and molecular tests [16-19], each possessing unique strengths and weaknesses. Viral isolation is the gold standard for diagnosis and takes advantage of viral replication in Madin-Darby canine kidney cells or other media to isolate viruses. Its application in routine diagnosis remains limited as an average input of 2-3 days in a biosafety level 3 laboratory is necessary to perform the propagation. In the preliminary discovery of H7N9, throat-swab specimens from suspected patients were propagated in the allantoic sac and amniotic cavity of 9-to-11-day old specific pathogen-free embryonated chicken eggs to isolate the pathogen [13]. Serological tests detect antibody response of a suspected patient which take days to develop but remain undetectable in fulminant cases. Rapid antigen tests, on the other hand, are commercialized antibody kits that detect influenza antigens within 20 minutes at high costs with little information about subtypes. Nonetheless, rapid antigen tests for $\mathrm{H} 1$, H3 and avian H5 subtypes have been developed despite a need for improved performance [20]. Comparatively speaking, molecular tests are the most sensitive and efficient diagnostic tools that confirm the presence of influenza viruses through amplification of target nucleic acids. They include reverse-transcription PCR (RT-PCR), real-time RT-PCR, nucleic acid sequence-based amplification, loop-mediated isothermal amplification (LAMP), microarray and pyrosequencing. RTPCR and real-time RT-PCR are similar techniques, the latter yielding quantitative results, which detect the highly conserved $M$ gene of type A influenza viruses and conserved regions of its HA gene. In spite of high start-up costs, real-time RT-PCR is widely utilized as first-line identification of influenza viruses due to its (i) readily available primer sequences; (ii) high sensitivity; (iii) quantitative results suggestive of prognostic significance. Currently, commercialized real-time RT-PCR assays have been developed for laboratory diagnoses of $\mathrm{H} 5 \mathrm{~N} 1$ and H1N1. In the discovery of H7N9, RNA was first extracted from throatswab samples of suspected patients to perform RT-PCR for seasonal influenza viruses $(\mathrm{H} 1, \mathrm{H} 3$ or $\mathrm{B}), \mathrm{H} 5 \mathrm{~N} 1$, severe acute respiratory syndrome coronavirus (SARS-CoV) and novel coronavirus. When such options were eliminated, self-designed primer and probe sets for $\mathrm{H} 1$ to H16 and N1 to N9 subtypes were used to identify viral subtypes [13].

Together with Neuraminidase (NA) inhibitors (oseltamivir, zanamivir, peramivir), adamantanes (amantadine, rimantadine), acting via $\mathrm{M} 2$ ion channel inhibition, serve as antiviral treatment against influenza viruses. In treating $\mathrm{H} 5 \mathrm{~N} 1$, adamantanes were found to be primarily resisted in Thailand, Cambodia and Vietnam. In view of such, oseltamivir was recommended as first-line treatment while oseltamivir phosphate or zanamivir as prophylaxis [21]. Nevertheless, 2 of $7 \mathrm{H} 5 \mathrm{~N} 1$ patients in Vietnam had displayed signs of oseltamivir resistance during treatment, suggesting considerable resistance rates of the drug [22]. Furthermore, clinical experience has denied the survival advantage of oseltamivir and its efficacy has not been verified [8,10,23-25]. While delayed treatment could be partly blamed, late preliminary drug administration should not be discouraged because pharyngeal viral loads were found to be undetectable among surviving patients after drug usage in small case series [22]. In treating H1N1, NA inhibitors failed to present survival advantage but its early administration was associated with reduced likelihood of severe clinical outcomes [26].

*Corresponding author: Yuanlin Song, M.D., Department of Pulmonary Medicine, Zhongshan Hospital, Qingpu Brach, and Shanghai Public Health Clinical Center, Fudan University, Shanghai Respiratory Research Institute, 180 Fenglin Road, Shanghai, 20032, China, Tel: 86-21-64041990-2422; E-mail: song.yuanlin@zs-hospital.sh.cn

Received July 02, 2013; Accepted July 04, 2013; Published July 08, 2013

Citation: Ou J, Lu S, Wu B, Bai C, Song Y (2013) The Epidemiology, Diagnosis and Treatment of H5N1, H1N1 and H7N9. J Pulm Respir Med 3: e129. doi:10.4172/2161-105X.1000e129

Copyright: (C) 2013 Ou J, et al. This is an open-access article distributed under the terms of the Creative Commons Attribution License, which permits unrestricted use, distribution, and reproduction in any medium, provided the original author and source are credited. 
Alarmingly, a significant increase in oseltamivir-resistant $\mathrm{H} 1 \mathrm{~N} 1$ viruses have been reported globally, probably as a result of prolonged infection among immunocompromised patients $[27,28]$. To guide the choice of therapy, neuraminidase inhibition assays may be performed to detect suspected antiviral resistance mutations. However, as the tests can only be carried out on viral cultures while certain virus mutants may be selectively enriched via viral propagation in Madin-Darby canine kidney cells, authenticity is questionable. Currently, limited experience remains when laboratory studies have verified sensitivity of H7N9 to neuraminidase inhibitors (oseltamivir and zanamivir) and resistance against amantadine and rimantadine [29-31].

In summary, the aforementioned influenza pandemics have taught us valuable lessons in diagnostics and public health management. They have reminded us the importance of preparation for upcoming influenza pandemics which may strike anytime and anywhere at any degrees. It is thus our liability to equip with relevant knowledge and react quickly towards such crises when they next prevail.

This study was supported by Shanghai Science and Technology Committee key grant 11411951102 and 12JC1402300, and National Natural Science Foundation grant 81170056 and Easter Scholar Program supported by Shanghai Municipal Education Committee.

\section{References}

1. http://www.who.int/influenza/human_animal_interface/influenza_h7n9/ RiskAssessment_7N9_13Apr13.pdf.

2. Gao HN, Lu HZ, Cao B, Du B, Shang H, et al. (2013) Clinical findings in 111 cases of influenza A (H7N9) virus infection. N Engl J Med 368: 2277-2285.

3. Subbarao K, Klimov A, Katz J, Regnery H, Lim W, et al. (1998) Characterization of an avian influenza $A(H 5 N 1)$ virus isolated from a child with a fatal respiratory illness. Science 279: 393-396.

4. Claas EC, Osterhaus AD, van Beek R, De Jong JC, Rimmelzwaan GF, et al (1998) Human influenza A H5N1 virus related to a highly pathogenic avian influenza virus. Lancet 351: 472-477.

5. http://www.who.int/csr/disease/avian_influenza/country/cases_ table_2009_05_15/en/index.html.

6. Novel Swine-Origin Influenza A (H1N1) Virus Investigation Team, Dawood FS, Jain S, Finelli L, Shaw MW, et al. (2009) Emergence of a novel swine-origin influenza A (H1N1) virus in humans. N Engl J Med 360: 2605-2615.

7. de Jong MD, Simmons CP, Thanh TT, Hien VM, Smith GJ, et al. (2006) Fatal outcome of human influenza A ( $\mathrm{H} 5 \mathrm{~N} 1)$ is associated with high viral load and hypercytokinemia. Nat Med 12: 1203-1207.

8. Tran TH, Nguyen TL, Nguyen TD, Luong TS, Pham PM, et al. (2004) Avian influenza A (H5N1) in 10 patients in Vietnam. N Engl J Med 350: 1179-1188.

9. Beigel JH, Farrar J, Han AM, Hayden FG, Hyer R, et al. (2005) Avian influenza A (H5N1) infection in humans. N Engl J Med 353: 1374-1385.

10. Chotpitayasunondh T, Ungchusak K, Hanshaoworakul W, Chunsuthiwat $S$, Sawanpanyalert P, et al. (2005) Human disease from influenza A (H5N1), Thailand, 2004. Emerg Infect Dis 11: 201-209.

11. Peiris JS, Yu WC, Leung CW, Cheung CY, Ng WF, et al. (2004) Re-emergence of fatal human influenza A subtype H5N1 disease. Lancet 363: 617-619.

12. To KF, Chan PK, Chan KF, Lee WK, Lam WY, et al. (2001) Pathology of fata human infection associated with avian influenza A H5N1 virus. J Med Virol 63: 242-246.

13. Gao R, Cao B, Hu Y, Feng Z, Wang D, et al. (2013) Human infection with a novel avian-origin influenza A (H7N9) virus. N Engl J Med 368: 1888-1897.

14. Gutierrez RL, Ellis MW, Decker CF (2010) Rhabdomyolysis and pandemic (H1N1) 2009 pneumonia in adult. Emerg Infect Dis 16: 565
5. Mak CM, Lam CW, Fong NC, Siu WK, Lee HC, et al. (2011) Fatal viral infectionassociated encephalopathy in two Chinese boys: a genetically determined risk factor of thermolabile carnitine palmitoyltransferase II variants. J Hum Genet 56: 617-621.

16. Kumar S, Henrickson KJ (2012) Update on influenza diagnostics: lessons from the novel H1N1 influenza A pandemic. Clin Microbiol Rev 25: 344-361.

17. Pasick J (2008) Advances in the molecular based techniques for the diagnosis and characterization of avian influenza virus infections. Transbound Emerg Dis 55: 329-338.

18. Suarez DL, Das A, Ellis E (2007) Review of rapid molecular diagnostic tools for avian influenza virus. Avian Dis 51: 201-208.

19. Wang R Taubenberger JK (2010) Methods for molecular surveillance of influenza. Expert Rev Anti Infect Ther 8: 517-527.

20. van Doorn HR, Kinh Nv, Tuan HM, Tuan TA, Minh NN, et al. (2012) Clinica validation of a point-of-care multiplexed in vitro immunoassay using monoclonal antibodies (the MSD influenza test) in four hospitals in Vietnam. J Clin Microbiol 50: 1621-1625.

21. Schünemann HJ, Hill SR, Kakad M, Bellamy R, Uyeki TM, et al. (2007) WHO Rapid Advice Guidelines for pharmacological management of sporadic human infection with avian influenza A (H5N1) virus. Lancet Infect Dis 7: 21-31.

22. de Jong MD, Tran TT, Truong HK, Vo MH, Smith GJ, et al. (2005) Oseltamivi resistance during treatment of influenza A (H5N1) infection. N Engl J Med 353: 2667-2672.

23. de Jong MD, Bach VC, Phan TQ, Vo MH, Tran TT, et al. (2005) Fatal avian influenza $\mathrm{A}(\mathrm{H} 5 \mathrm{~N} 1)$ in a child presenting with diarrhea followed by coma. $\mathrm{N}$ Engl J Med 352: 686-691.

24. Kandun IN, Wibisono H, Sedyaningsih ER, Yusharmen, Hadisoedarsuno W, et al. (2006) Three Indonesian clusters of H5N1 virus infection in 2005. N Engl J Med 355: 2186-2194

25. Oner AF, Bay A, Arslan S, Akdeniz H, Sahin HA, et al. (2006) Avian influenza A (H5N1) infection in eastern Turkey in 2006. N Engl J Med 355: 2179-2185.

26. Muthuri SG, Myles PR, Venkatesan S, Leonardi-Bee J, Nguyen-Van-Tam JS (2013) Impact of neuraminidase inhibitor treatment on outcomes of public health importance during the 2009-2010 influenza $A(H 1 N 1)$ pandemic: a systematic review and meta-analysis in hospitalized patients. J Infect Dis 207 553-563.

27. Weinstock DM, Gubareva LV, Zuccotti G (2003) Prolonged shedding of multidrug-resistant influenza $A$ virus in an immunocompromised patient. N Engl J Med 348: 867-868.

28. Ison MG, Gubareva LV, Atmar RL, Treanor J, Hayden FG (2006) Recovery of drug-resistant influenza virus from immunocompromised patients: a case series. J Infect Dis 193: 760-764.

29. http://www.ecdc.europa.eu/en/publications/Publications/AH7N9-China-rapidrisk-assesement.pdfhttp://www.ecdc.europa.eu/en/publications/Publications/ AH7N9-China-rapid-risk-assesement.pdf.\%20

30. Yang FF, Wang JL, Jiang L, Jin JL, Shao LG, et al. (2013) A fetal case caused by novel H7N9 avian influenza a virus in China. Emerging Microbes and Infections. doi:10.1038/emi.2013.22.

31. http://www.who.int/influenza/human_animal_interface/faq_H7N9/en/. 